\title{
A COMPLEMENTARIDADE SEGUNDO N. BOHR: PELAS RELAÇÕES QUÂNTICAS E PELOS FUNDAMENTOS
}

\section{COMPLEMENTARINESS ACCORDING TO BOHR: QUANTUM RELATIONS AND FOUNDATIONS}

\author{
Ramiro Délio Borges de Meneses* \\ Universidade Católica Portuguesa
}

Resumo: A nova forma de causalidade estatística, Niels Bohr deu-lhe o nome de princípio da complementaridade, em dois modos de compreender a "natureza física». As relaçóes de complementaridade, expressando os limites dos conceitos clássicos, pretendem apresentar nova leitura sobre os fenómenos atómicos, em termos dos conceitos da física clássica. N. Bohr propóe um novo princípio de complementaridade. Assim, serão analisados os fundamentos ontológicos, gnoseológicos e as aplicaçôes do referido princípio da Mecânica Quântica.

Palavras-chave: Niels Bohr, princípio da complementaridade, Mecânica Quântica, Ontologia, Gnoseologia, Filosofia e aplicaçôes.

ABSTRACT: Bohr called this novel type of statistical causality complementariness; two mutually exclusive modes of description were said to be complementary, and they then conditioned each other in a statistical way. This relation of complementariness, expressing the limitations of the classical concepts, made it possible to give a complete and consistent account of atomic phenomena in terms of these classical concepts of physics.According to N. Bohr, there is an effort to achieve a more and more precise formulation of the idea of complementariness, and to develop its wider ontological or gnoseological implications as well as to make the phenomenological applications of quantum mechanics to other sciences possible, in this article.

KeyWords: Niels Bohr, principle of complementarity, Quantum Mechanics, Ontology, Gnoseology, Philosophy, and applications.

* Investigador do Centro de Estudios Filosóficos, Centro Regional de Braga. Profesor Auxiliar do Instituto de Ciências da Saúde do Norte - Gandra. E-mail: borges272@gmail.com 


\section{Introdução}

O princípio da «complementaridade» foi elaborado, em 1927, por N. Bohr. Este físico dinamarquês foi laureado, em 1922, com o Prémio Nobel da Física, pelos seus trabalhos sobre a estrutura atómica, tendo concebido um modelo planetário. Porém, não foi confirmado experimentalmente o modelo de Bohr, sucedendo que a fórmula da qual se obtém, para as transiçôes atómicas, permitem interpretar com rigor as linhas espectrais dos átomos. De facto, seguidamente sirgiram as incongruências do modelo. Se o átomo de $\mathrm{H}_{1}$ (hidrogénio) fosse plano, entáo poder-se-ia realizar uma experiência, que poria em evidência tal facto. Assim, por exemplo, fazendo com que os planos de todos os átoimos do vapor de hidrogénio seriam paralelos uns aos outros, fazendo fluir o gás de maneira diferente em diferentes direcçóes. Adequadamente, a crítica ao dito modelo conduziu ao estabelecimento da Mecânica Quântica.

Para sistematizar os estados estacionários do átomo, Heisenberg construíra a Mecânica das Matrizes, a qual parte do princípio da correspondência de Niels Bohr, ao aplicar à natureza física os dois novos conceitos matemáticos de matriz e de probabilidade. Foi nas "crises quânticas» (Solvay, 1927) que Heisenberg enunciou o célebre princípio do indeterminismo ou das relaçóes de incerteza:

$$
\Delta x \cdot \Delta p=h / 4 \pi=1 / 2 h
$$

Assim, segundo Heisenberg, não se pode definir, ao mesmo tempo, a posição e a quantidade de movimento duma partícula. Surge sempre um erro que será igual ao valor dado pelo limite «h» ou quantum actions de M. Planck. Na verdade, a constante de Max Planck h conhece-se com uma incerteza de o,68 partezs por milhão. $\mathrm{O}$ seu valor será o seguinte: $\mathrm{h}=6,626 \times 10^{-34} \mathrm{~J}$. Este princípio possui relaçóes métricas com o princípio da complementaridade de N. Bohr. ${ }^{1}$

Contudo, apesar de Sommerfeld ter aperfeiçoado o modelo bohreano do átomo de Hidrogénio, a órbita não é circular, mas elíptica, que pelos números quânticos (três graus de liberdade) desenha uma roseta de precessão. ${ }^{2}$ Natural-

${ }^{1}$ Cf. SOUSA ALVES, V. M. "Crítica da Mecânica Quântica», in: Revista Portuguesa de Filosofia, 50 (Braga, 1994), 39.

2 Cf. BORN, M. Física Atómica, $3^{a}$ edição,tradução do inglês, Fundação Calouste Gulbenkian, Lisboa, 1969, 114-116. 
mente, continuavam por resolver duas antinomias entre a mecânica clássica e a nova teoria quântica.

A segunda antinomia refere que o fenómeno da luz é ondulatório, porque origina franjas de interferência e é partícula, em movimento, porque produz o efeito fotoeléctrico e a dispersão de Compton. Esta antinomia é resolvida por Niels Bohr no princípio de «complementaridade», que afirma ser a natureza dotada por duas imagens de onda e de partícula, como complementares, porque descrevem dois aspectos do mesmo fenómeno.N. Bohr já tinha enunciado, em 1923, o princípio da correspondência (para casos limites de grandes massas e de órbitas de grandes dimensões, a Mecânica Quântica coincide com a Mecânica Clássica) para resolver a antinomia quântica, segundo a qual o movimento dos electróes orbitais obedece às equaçóes da Mecânica Clássica, mas as radiaçóes de energia só satisfazem as condiçôes quânticas. ${ }^{3}$ As duas mecânicas estão entre si como a assimptota para uma curva. Niels Bohr escreveu a descoberta do $\mathrm{H}_{1}$, ensinandonos que as teorias clássicas da Física são idealizaçóes, que não podem ser aplicadas sem ambiguidades, senão no limite, em que todas as acçôes, postas em jogo, são grandes por relação ao quantum actionis. Procuramos, assim, determinar, além da exposição quântica do princípio da complementaridade, algumas posições críticas do princípio da complementaridade, para depois apresentar uma metateoria que interpreta e/ou fundamenta o valor e limites das teorias científicas, também chamada crítica ou filosofia das ciências (epistemologia). Além das aplicaçóes do princípio apresentamos os fundamentos ontológicos e gnoseológicos.

\section{Sentido quântico da complementaridade}

2.1 Este princípio fundamental da Mecânica Quântica pretende explicar a observação dos aspectos antinómicos dos microfenómenos, desde o corpuscular ao ondulatório. Para descrever os estados estacionários do átomo, Heisenberg elabora a Mecânica Quântica das Matrizes, onde se escrevem — seriados pelos sub- índices - os valores das «intensidades das frequências»" e Schrödinger apresenta a Mecânica Quântica Ondulatória. Mas, nenhum dos dois formalismos

${ }^{3}$ Cf. N. BOHR «The structure of the atom», in: Nobel Lectures on Physics, Elsevier Publishing Company, Amsterdam, 1965, 5-6.

${ }^{4}$ Cf. HEISENBERG, W Die physikalischen Prinzipien der Quantentheorie, Bibliographisches Institut, Mannheim, 1958, 8-16. 
matemáticos, equivalentes, nos fornece a «imagem» clara e precisa do fenómeno total, como, por exemplo, a passagem do electrão na câmara de Wilson.

Então a escola de Copenhagen, para clarificar o problema, na sua interpretação estatística, seguiu duas vias: princípio da incerteza e o princípio da complementaridade. As duas imagens (corpuscular e ondulatória) são duas descriçôes complementares da mesma realidade, porque os dois operadores dos valores reais, não sendo comutativos, representam grandezas físicas complementares: Não será, pois, possível o conhecimento rigoroso e simultâneo das grandezas físicas, que caracterizam a partícula e a onda, sendo estes conceitos analógicos aos da Mecânica Clássica. Na matéria, bem como na radiação e, em geral, na luz, em particular, introduz-se a ideia do corpúsculo e das ondas simultaneamente; ou, por outras palavras, tanto num caso como no outro, teremos de assumir a existência dos corpúsculos acompanhados pelas ondas. Todavia, os corpúsculos e ondas não podem ser independentes um do outro. Segundo N. Bohr, existem dois aspectos complementares da realidade e poderá ser possível estabelecer um certo paralelismo entre o movimento de um corpúsculo e a propagação das ondas associadas. O primeiro e grande objectivo, entretanto, foi definir a existência daquele paralelismo. ${ }^{5}$

2.2 Dialecticamente poderemos dizer que o «princípio da complementaridade» aparece como síntese:, onde a "partícula-onda» será a formula definitiva entre a partícula, como tese, e a onda revelando-se como antítese. Trata-se de um «enunciado diádico», onde a natureza se revela: naturans, naturatus et naturaturus:

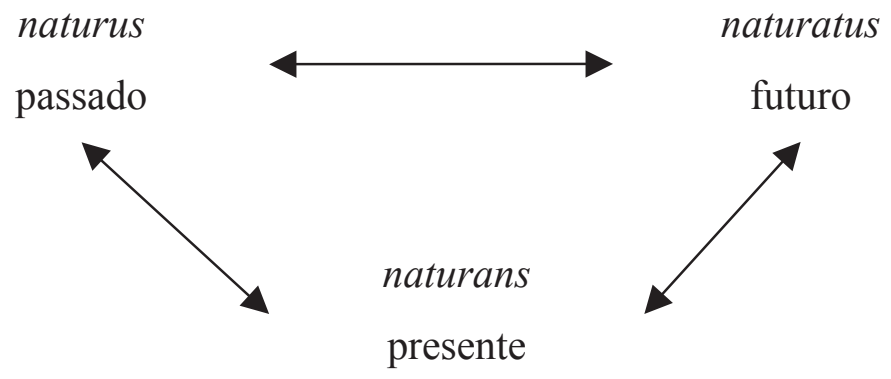

Através do princípio da complementaridade surgem duas linguagens para falar da natureza. A própria natureza reveste-se de duas formas naturans et naturata.

5 Cf. IKENBERRY, E. Quantum Mechanics, for mathematicians and physicists, Oxford University Press, New York, 1962, 28. 
$\mathrm{Na}$ ordem física, a posição de uma partícula poderá obviamente ser observada como um "ponto acontecimento» $\left(\Delta x_{i}\right)$ e o momento surge como um «acontecimento -impulso" $\Delta p=m \cdot \Delta v$. Somente se a partícula possui uma grande massa, entáo a Mecânica de Newton poderá ser aplicada, podendo falar-se de uma partícula, que tem uma posiçáo e um momento e poderemos calcular o momento de duas posiçóes pela fórmula: $p=m \cdot d x / d t$.

De acordo com N. Bohr, o mundo físico não pode ser descrito por uma linguagem coerente. Existem duas linguagens, segundo o princípio de Bohr, que serão complementares uma da outra. Uma náo é sem a outra. Em física quântica, a onda necessita do corpúsculo e este precisa do primeiro elemento físico. $\mathrm{O}$ princípio da complementaridade vem assegurar a relação entre estas duas formas de existir como "partícula-onda", segundo L. de Broglie. Umas vezes, somos obrigados a falar do «momento de partículas» ou impulso de acontecimentos. Se nós fazemos uso de todas as informaçóes possíveis, acerca do presente estado do mundo, entâo poderemos usar ambas as linguagens. Poderemos "prever» acontecimentos que a ciência actual é inapta para os predizer. Este aspecto do mundo é aquilo a que $\mathrm{N}$. Bohr chamou de aspectos complementares. ${ }^{6}$ Este princípio tem a vantagem de regular a natura naturans e a natura naturata, devido à dualidade do comportamento físico e suas relaçôes. Desta feita, a "partícula» será natura naturata, enquanto a "onda» será natura naturans, reciprocamente. Uma não existe sem a outra, tal como analisa Heisenberg.

${ }^{6}$ Cf. FRANK, Ph «Foundations of Physics», in: International Encyclopedia of Unified Science, Volume 1, number 7, At the University Press, Chicago, 1950, 50. 


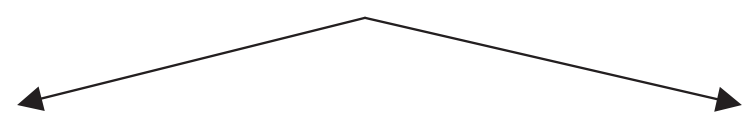

Descrição dos fenómenos no espaço e no tempo

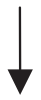

Relações de Incerteza

$$
\begin{aligned}
& \Delta p \cdot \Delta x \sim h \\
& \Delta E \cdot \Delta t \sim h
\end{aligned}
$$

Esquema matemático que não corresponde ao espaço e ao tempo

Causalidade aleatória

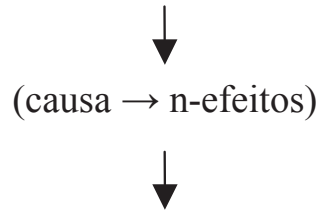

Ausência de lugar

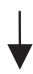

sem o terminus continentis imoblis primus

2.3 A relação de incerteza poderá igualmente ser deduzida a partir da seguinte ideia geral: se nos propusermos formar um «feixe de ondas», que ocupe uma distância finita na direcção do eixo dos X, a partir de feixes de ondas separadas, necessitamos, para esse fim, de dispor de ondas monocromáticas com uma dada gama de frequência finita, isto é, por ser: $\lambda=h / p$, de partículas cujas quantidades de movimento formem um espectro finito. Mas, pode demonstrarse, de forma geral, que a extensão linear do feixe de ondas está ligada com o espectro requerido pelas quantidades de movimento na relação: $\Delta p_{i} \cdot \Delta x_{i} \sim h$. Será evidente que, quanto à ordem de grandeza, a anterior relação é válida para qualquer forma de feixe de ondas. Em função do princípio de Heisenberg, Bohr costumava asseverar que os aspectos corpuscular e ondulatório são complementares, significando que se demonstrarmos o carácter corpuscular de uma experiência, será impossível provar, ao mesmo tempo, sed non sub eodem aspectu, o seu carácter ondulatório e, assim, inversamente. ${ }^{8}$ Este aspecto terá implicaçóes

7 Cf. HEISENBERG, W. Physikalische Prinzien der Quantentheorie, Bibliographisches Institut, Mannheim, 1958, pp. 48-49].

${ }^{8}$ Cf. BORN, M. Física Atómica, tradução do inglês por Egídio Namorado, $4^{a}$ edição, Fundaçâo Calouste Gulbenkian, Lisboa, 1986, pp. 111-112. 
na causalidade e, naturalmente, o dualismo onda-corpúsculo e a indeterminação estão nele essencialmente envolvidos, pela métrica das observaçóes físicas, nos coage a abandonar qualquer tentativa de instituir uma "teoria determinista», que terá implicaçôes na ordem filosófica, desde a gnoseologia até à ontologia, passando pela fenomenologia. ${ }^{?}$

2.4 O princípio da complementaridade pode ser quanticamente generalizado, assim consideramos a complementaridade entre amplitudes e fases, que implica o formalismo de Schrödinger e de Heisenberg. Esta perspectiva pode aparecer como crítica e reflexão ao pensamento de Bohr. Será necessário pensar com um só corpúsculo, aquilo que estabelece a propriedade não somente para os bosôes, mas também para os fermióes. Já existem experiências reais do ecran de Young atravbessada por um feixe de paqrtículas ou de fotóes com os indivíduos suficientemente distanciados para assegurar que ebfrentem no ecran isolados. As interferências dos electrōe $4 \mathrm{~s}$ 'ao atravessarem um a um, as redes de Young será, segundo encosta realizada no ano de 2005, como uma das mais belas experiências da Física.

Poderemos excluir da nossa perspectiva aquela que é a formulação tradicional, chamada complementaridade entre as noçóes de onda e de corpúsculo, atendendo àquilo porque se entendeu por onda e pelo sentido do corpúsculo.

Mas segundo o carácter obrigatório do número de ocupação, numa medida daquela fase de onda, não o será vice-versa. Retomemos a célebre experiência de pensamento das franjas de Young, determinada por uma onda $\psi$, portadores de um só corpúsculo. Se queremos referir as franjas por acumulação do impacto sobre uma placa fotográfica, ao repetir a experiência um grande número de vezes, será necessário que as duas «lentes» estejam abertas. Se, ao contrário, queremos determinar o número de ocupação de uma das duas ondas quasi-cilíndricas, então será necessário fechar a outra abertura. Mas, as franjas desaparecem, não podendo falar-se da diferença de fases destas duas ondas. A diferença de fases, entre a onda e o corpúsculo, e os números de ocupação das duas ondas quasicilíndricas não são simultaneamente determinadas. A defasagem entre as duas ondas, compondo a onda total, não será medida, se considerarmos um número grande, mas contáveis, de corpúsculos, sobre a onda total.

9 Cf. HEISENBERG, W. et alii Discussione sulla fisica moderna, traduzione dal tedesco, P. Boringhieri, Torino, 1960, 35-58. 
2.5 Sendo uma onda $\psi$ portadora de um só corpúsculo, que cai sobre um espelho semi-transparente, a onda $\psi$ separa-se em duas ondas, uma $\psi_{1}$ transmitida e outra $\psi_{2}$ reflectida, que são calculadas por meio de métodos usados pela Óptica Clássica. Sendo $f=1, \mathrm{f}_{1}$ e $\mathrm{f}_{2}$, tais que $f_{1}+f_{2}=1$, as intensidades reais positivas, destas três ondas, quer dizer os fluxos correntes de Gordon, surgem através de uma hiper-superfície de espaço semelhante. Os números não-inteiros $\mathrm{f}_{1}$ e $\mathrm{f}_{2}$ representam as probabilidades a priori de reencontrar o corpúsculo sobre a onda $\psi_{1}$ ou sobre a onda $\psi_{2}$, depois de medidas as intensidades das ondas $\psi_{1}$ e $\psi_{2}$, que serão tornadas inteiras, como os valores 1 e 0 , ou 0 e 1 .Imaginemos que um observador $\mathrm{O}_{1}$ opera sobre o feixe $\psi_{1}$, e um observador $\mathrm{O}_{2}$ sobre o feixe $\psi_{2}$, cada um poderá fazer passar o seu feixe por meio de um écran, para ver se ele encontrará ou não o corpúsculo. Segundo O. Costa de Beauregard: «puisque le critère de l'objectivité, c'est l'unanimité témoins, nous devons conclure que, la grâce séparatrice et, au moins, un compteur de particules étant en place, c'est objectivement que le corpuscule se trouve présent sur l'un ou l'autre de deux faisceaux émergents, et absent de l'autre. Nous retrouvons ainsi le fait, déjà mis en lumière, de l'objectivité à l'intérieur d'un même programme de mesures, mais sous une forme rendue très frappante par la séparation en deux du faisceau initial». ${ }^{10} \mathrm{~N}$. Bohr foi criticado, por Einstein, na sua interpretação :«Si, dit Einstein, sans aucunement agir sur un certain être physique l'on peut cependant faire une mesure d'on résulte la connaissance exacte d'une propriété du premier être alors il existe un élément correspondant d'objectivité de cet être. C'est l'affirmation du caractère objectif d'un résultat de mesure. (...) A cela Bohr répond bien sûr, il ne peut être question d'un dérangement mécanique du système en étude durant la dernière étape critique de l'acte de mesure. (...) C'est l'affirmation du caractère arbitraire de la forme de la question posée à la Nature et du caractère aléatoire de la réponse reçue». ${ }^{11}$

A determinação simultânea da posição e da velocidade é realmente impossível e é incompatível com as leis quânticas firmemente alicerçadas na experiência.

A origem desta dificuldade aparece pelo facto de sermos complicados a usar palavras da linguagem vulgar, quando queremos descrever um fenómeno, não pela análise lógica ou matemática, mas por uma representação que apele à imaginação. A linguagem vulgar desenvolveu-se pela experiência quotidiana e não

${ }^{10}$ Cf. BOHR, N. The Theory of Spectre and Atomic Constitution, At the University Press, Cambridge, 1922, 7-15.

${ }^{11}$ Cf. Ibidem, 28-29. 
pode nunca ultrapassar estes limites. A física clássica restringiu-se ao uso de conceitos, desta espécie, pela análise dos movimentos elementares: partículas móveis e ondas.

Naturalmente que,por um lado,qualquer processo poderá ser interpretado seja em termos de corpúsculos, seja em termos de ondas; mas, por outro lado, está para além das nossas possibilidades provar que estamos lidando com corpúsculos ou com ondas, pois não podemos determinar simultaneamente todas as outras propriedades, que caracterizam um corpúsculo ou uma onda. Poder-se-á afirmar que as descrições ondulatória e corpuscular devem ser encaradas como modos «complementares» de conceber o mesmo e único processo objectivo, o qual, só em casos limites e definidos, admite uma interpretação intuitiva completa. Será precisamente a possibilidade limitada de realizar medições, que define as fronteiras entre os nossos conceitos de partícula e de onda. Por aqui vamos verificando que o princípio da complementaridade é mais um princípio, de ordem filosófica, do que um postulado da métrica quântica.

\section{Ascensão e queda da complementaridade}

3.1 Os físicos mais avançados, segundo M. Bunge, julgavam que tinham de enfrentar duas dualidades: a natureza dual do campo electromagnético (Maxwell) e a possível dualidade da matéria. A partir desta dupla dualidade, não havia mais do que um pequeno passo a dar para a conjuntura ontológica, de que toda a entidade física tem aspectos corpusculares e ondulatórios. Esta é a tese do dualismo geral, como hipótese metafísica, porque diz respeito à natureza básica de todo o existente. Quando a Mecânica Quântica foi elaborada, as relaçôes de «incerteza de Heisenberg» foram interpretadas segundo o «dualismo físico». Naturalmente, o princípio de complementaridade de N. Bohr nunca foi afirmado sem ambiguidade, para não dizer claramente compreendido. Seria, de facto, uma especificação ou particularização porque, além de afirmar a dualidade, declarava que quanto mais um dos dois aspectos é realçado, tanto mais o seu complemento era ofuscado. O princípio da complementaridade pretendia dizer respeito mais ao complexo sujeito-objecto, do que aos microssistemas, existindo autonomamente.

De facto, as formulaçóes ortodoxas do princípio não afirmam que os traços corpusculares e ondulatórios de um microssistema se equilibram entre si. Em vez disso, declaram que aquilo que pode ser «complementar» é ou um par de dispositivos experimentais macroscópicos, incluindo o observador, ou um par 
de descriçóes dos resultados de operaçóes conduzidas com a ajuda dessas montagens laboratoriais ou com um par de conceitos. A complementaridade fortalece o «dualismo» ao torná-lo ligeiramente mais preciso, mas por, outro lado, enfraquece o "dualismo» ao não conseguir atribui-lo à natureza das coisas em si, como os átomos, no espaço livre, não teriam uma «natureza dual». Eles seriam apenas ficçôes de uma imaginação não disciplinada pela filosofia de Copenhague, centrada no sujeito. ${ }^{12}$ Visto que os dispositivos experimentais e os seus resultados podem supostamente ser descritos em termos clássicos, o princípio de complementaridade permanece neste lado da Mecânica Quântica e da Electrodinâmica Quântica. In stricto sensu, a "complementaridade de Bohr» não é um enunciado teórico-quântico, enquanto não disser respeito a microssistemas. Trata-se, pois, de um enunciado lógico-filosófico, tanto mais que se trata de um princípio didáctico-pedagógico. Assim, o princípio de complementaridade não é um princípio, porque nada implica e, ainda, segundo a lógica simbólica, nenhum teorema se segue dele. O pseudo- princípio da complementaridade não é, entáo nem um princípio, nem um teorema, dado que não é válido para os campos. E na teoria quântica avançada das partículas, pela segunda quantização de Feynemann, o campo é tratado como uma coisa primordial. ${ }^{13}$

Logo, no caso dos electrôes, ou dos mesôes, o campo da matéria é olhado como a entidade primária, ao passo que as partículas ou, antes, as entidades semelhantes às partículas, são apenas quanta do campo, ou seja, aparecem como pedaços do campo. Como representam um valor próprio do operador do número de ocupação, os quanta do campo não são partículas, em sentido clássico. Assim, segundo a nova mecânica quântica, teremos a hamiltoniana de um sistema completo:

$$
\text { átomo + campo radiante, }
$$

concebido como sistema dinâmico único. A hamiltoniana do movimento não relativista de um «negatão atómico» no campo central será:

$$
\text { Hmatéria }=p^{2} / 2 m+\phi(r)
$$

12 Cf. BUNGE, M. Philosophy of Physics, D. Reidel Publishing Company, Dordrecht, 1973, 123-125.

13 Cf. Ibidem, p. 124. 
A hamiltoniana do campo radiante será:

$$
\text { Hсатро }=1 / 2 \sum_{u}\left(P_{u}^{2}+\omega_{u}^{2} \cdot Q_{u}^{2}\right)
$$

Ligando as duas equaçóes, obteremos o hamiltoniano $\mathrm{H}_{0}$ do campo puro e da matéria representada pelo negatão atómico:

$$
H_{0}=\text { Hmatéria }+ \text { Hcampo }=p^{2} / 2 m+\vec{\phi}(\vec{r})+1 / 2 \sum_{u}\left(P_{u}^{2}+\omega_{u}^{2} \cdot Q_{u}^{2}\right) \cdot{ }^{14}
$$

Consequentemente, não há lugar para a «complementaridade» nas áreas mais específicas da teoria quântica, nem a fortiori, em qualquer das teorias fenomenológicas, tais como o formalismo matricial das incertezas, que evitam uma descrição detalhada do campo. Então, como se explica a sobrevivência da complementaridade? A principal razáo, segundo M. Bunge, parece ser a sua utilidade. $\mathrm{Na}$ verdade, a «complementaridade» explica satisfatoriamente muitas dificuldades e dá conta da experiências de duas espécies: experiências pensadas, que nunca foram realizadas e experiências reais que nunca foram computadas, em termos teórico-quânticos.

Uma vez aceite o princípio da complementaridade, este poderá ser usado para consagrar obscuridades e inconsistências. No tocante à experiência, que alegadamente ilustra o princípio, ela é, de facto imaginária ou está para além do alcance da teoria. Entre os primeiros encontra-se o microscópio de raios gama de Heisenberg e a experiência do obturador de Bohr na discussão com Einstein. Visto que não têm poder de confirmaçáo, devemos deixá-los de lado. Entre as experiências de segunda espécie, destacam-se as experiências da difracção. Infelizmente, a difracção, por uma única fenda, só foi calculada para uma fenda infinitamente longa e para uma onda monocromática de De Broglie. O cálculo disponível é aproximado e os seus resultados chocam de frente com as desigualdades de Heisenberg. A fortiori, a muito discutida experiência da dupla fenda nunca foi calculada exactamente na Mecânica Quântica, para não falar na Electrodinâmica Quântica. Na verdade, só algumas fórmulas são usadas nas discussôes qualitativas destas experiências, mas elas são tiradas da teoria geral, não resultando de uma aplicação dela e essas circunstâncias especiais. Com efeito, também acontece que alguns padrôes de difracção são mostrados, mas eles são tirados de experiências reais, até agora não calculados ou são empréstimos da óptica clássica.

${ }^{14}$ Cf. SCHIFF, L. I. Quantum Mechanics, Mac Graw-Hill,New York, 1955, 68-120. 
A discussão destas experiências, em termos de complementaridade,é verbal e analógica. Naturalmente, a complementaridade não é parte e parcela da teoria quântica. A complementaridade, embora parecesse razoável nos primeiros tempos da teoria quântica, quando se pensava em termos de imagens clássicas, esgotará, segundo Bunge, qualquer potencial que pudesse ter tido e tornou-se uma desculpa para a obscuridade e inconsistência, favorecendo a teoria dos "parâmetros ocultos». ${ }^{15}$

3.2 A complementaridade de Bohr oscila entre uma descrição espaciotemporal e uma descriçáo causal, que se poderá reduzir entre a posição e o tempo, por um lado, e, por outro, a impulsão e a energia. A essência da física quântica poderá exprimir-se pelo "postulado de Bohr», o qual refere que todo o processo atómico apresenta um carácter de descontinuidade ou de individualidade, completamente estranho às teorias clássicas e caracterizado pelo quantum actionis de Planck. ${ }^{16}$

Pese embora o princípio de complementaridade náo apareça descrito na maioria dos tratados de Mecânica Quântica, está consignado filosoficamente com algum interesse, uma vez que esta complementaridade logicamente se traduz numa relação n-ádica, que existe entre as notas ou elementos de um conceito, de uma proposição ou de n-proposiçôes, de modo a formar um todo de sentido semântico, $x R y$, aparecendo como uma operaçáo formal da teoria dos conjuntos: $A<B$. O sentido prático da complementaridade, segundo N. Bohr, é reduzido, mas tal não implica que não haja pouco significado em Mecânica Quântica. Por estas razóes, o princípio de complementaridade refere-se com interesse marcadamente gnoseológico, como veremos ao descrever a sua fundamentação filosófica.

3.3 Será interessante observar que, no ano de 1927, a situação era tal que nem o modelo corpuscular, nem o ondulatório eram adequados para explicar a nova realidade do mundo sub- atómico. O princípio de Bohr, muito embora surjam muitas críticas, segundo E. Agazzi, desempenhou um papel significativo na filosofia oficial da Mecânica Quântica.

${ }^{15}$ Cf. SAKURAI, J. J. Modern Quantum Mechanics, Addison-Wesley Publishing Company, New York, 1998, 106-226.

${ }^{16}$ Cf. DIRAC, P. A. M. The Principles of Quantum Mechanics, Clarendon Press, Oxford, $1958,18-56$. 
Um dos aspectos mais curiosos prende-se com o facto de este princípio nunca ter sido enunciado de modo claro e unívoco, especialmente no que se refere ao enunciado do seu criador Niels Bohr. Há uma grande vacuidade sobre elementos quânticos, relativamente às afirmaçóes fundamentais deste princípio. Se se toma em consideração as declaraçóes de Bohr, o princípio em questáo parece referir-se a descriçóes dos fenómenos. Por causa dos seus contrastes, as manifestaçóes dos sistemas atómicos, sob diversas condiçóes experimentais, devem ser entendidas como «complementares», no sentido em que todas elas estão perfeitamente definidas e que juntas esgotam todo o conhecimento, relativamente aos objectos estudados. $\mathrm{O}$ formalismo quântico, cujo fim será a compreensão das observaçôes feitas sob condiçôes experimentais, susceptíveis de serem descritas mediante simples conceitos físicos proporciona uma descrição completamente exaustiva de um amplo domínio da experiência. ${ }^{17}$ Analogamente, Bohr fala outras vezes de «imagens». Os dados obtidos, em condiçóes experimentais distintas, náo se podem recolher numa imagem singular, mas numa «imagem dual» (complementares), no sentido em que somente a totalidade dos fenómenos esgota a possibilidade de informação relativamente aos objectos. A vacuidade, não voluntária, criada por N. Bohr ao falar de descrições ou «imagens», esteve menos acentuada em outros autores. W. Pauli chama «complementares» aos dois conceitos clássicos, não duas afirmaçóes e salienta: se a possibilidade de usar um conceito clássico está na relação de exclusão com a possibilidade de utilizar outros, então chamamos de complementares a estes dois conceitos, por exemplo, as coordenadas de posição e do impulso de uma partícula. ${ }^{18}$ Náo será difícil ver que o conceito de complementaridade se lê de uma maneira distinta. Não se trata já, como no caso de Bohr, de duas descriçóes clássicas, mutuamente excluídas dos factos atómicos, mas de dois conceitos que, pertencendo a uma mesma descriçáo clássica, como a corpuscular, não se pode usar simultaneamente, sendo modificado por Carl von Weiszäcker. ${ }^{19}$ Ao menos o que se pode dizer é que considerar equivalentes formulaçóes da complementaridade, tais como a exposta por Bohr, por uma parte,e, por Pauli, por outra, equivale a criar uma certa confusão, a qual remonta ao mesmo Bohr. Segundo o físico dinamarquês, observa-se, em variadas circunstâncias, a impossibilidade de combinar, totalmente, a coordenação espacio-temporal, por um lado, e a determinação da energia e a quantidade do movimento, por outro,

17 Cf. AGAZZI, E. Temas y problemas de Filosofía de la Física, Editorial Herder,Barcelona, 1978, 130.

18 Cf. PAULI, W. Pauli Lectures on Physics, volume 5, Wave Mechanics, translated by H. R. Lewis and S. Margulies, MIT Press, Cambridge, 1973, 38-69; 105-126; 127-164.

19 Cf. VON WEIZSHECKER, C. F. E. «El significado de la teoría cuántica», in: Analogia, 5, 2 (México, 1991) 10-12. 
ficando a mesma estrutura, que em princípio devem ter os aparelhos capazes de permitir a determinação de uma ou de outra. Este raciocínio, cuja essência é evidentemente o conteúdo do princípio de Heisenberg, deveria conduzir a uma definição da complementaridade do tipo de Pauli.

Pelo contrário, Bohr passa, sem nenhuma justificação, ao seu tipo de complementaridade, isto é, aquele que se refere às descrições classicamente incompatíveis: deveremos estar preparados, afirma, frente ao facto de que os dados obtidos mediante dispositivos experimentais mutuamente excluídos — como os que usam para determinar a posição e o impulso- podem mostrar contrastes até agora não observados e aparecer como contraditórios à primeira vista. Será, necessariamente, por esta situação, na qual se recorre à noção de complementaridade, para elaborar um esquema suficientemente amplo, que proporciona a explicação das regularidades fundamentais, que não podem ser incluídas numa descrição única. ${ }^{20}$

O facto de que devemos estar preparados para aceitar uma complementaridade entre descriçóes reunidas entre si, não resulta absolutamente como consequência lógica de que estamos obrigados a contentarmos com medidas não plenamente determinadas de certas grandezas físicas. O princípio de complementaridade foi apresentado como uma espécie de estado de necessidade imposto pelas relaçóes de indeterminação.

Max Born segue plenamente Niels Bohr, neste tipo de raciocínio. Tal facto não é verdadeiro se o princípio de complementaridade se entende no sentido de Bohr — complementaridade entre descriçóes—, enquanto resulta demasiado trivial, que se entenda no sentido de Pauli, posto que, neste caso, surge uma simples reformulação verbal do mesmo princípio de indeterminação. ${ }^{21}$ Para não admitir um status provisional para o princípio da complementaridade, e ao mesmo tempo para suster as acusaçôes de contradição, os defensores da complementaridade encontraram um precioso auxílio ao princípio de Heisenberg. ${ }^{22}$

${ }^{20}$ Cf. BOHR, N. Collected Works, volume 2, edited by U. Hoyer, North-Holland Publishing Company, Amsterdam, 1981, 7-10.

${ }^{21}$ Cf. BORN, M. Física Atómica, 1968, 107-109.

${ }^{22}$ Cf. HEISENBERG, W. Physics and Philosophy, George Allen and Unwin, London, 1958, 115-126. 
É indiscutível e historicamente documentável que Bohr não chegou à ideia de complementaridade pelo conhecimento do princípio de Heisenberg, mas não é menos certo que no referido princípio se encontra uma espécie de confirmação psicológica e lógica. Segundo a perspectiva de N. Bohr, o princípio da indeterminação coloca o preço a pagar pelo uso de noçóes complementares, mas irreconciliáveis, e mostrava como não se chegaria a uma contradição, porque jamais se chegariam a cimentar simultaneamente os dois aspectos complementares e irreconciliáveis de um mesmo fenómeno. ${ }^{23}$

Mas, esta justificação foi exaustivamente repetida por muitos defensores da «Escola de Copenhaguen», mas a sua força aparente repousa precisamente numa confusão entre os dois aspectos distintos da noção de complementaridade.

Uma coisa é a situação nova que se dá na microfísica, que proíbe o uso simultâneo, com uma precisão superior a certo limite, dos dois conceitos mutuamente compatíveis (posição e velocidade), cujo significado provém da Mecânica Clássica, enquanto que outra coisa distinta será admitir que a nova situação parece impor-se ao uso simultâneo de dois conceitos de origem clássico, mutuamente incompatíveis (onda e corpúsculo). O primeiro caso não coloca problemas de compatibilidade lógica, de não contradição intrínseca, dado que coloca o problema da inadequação dos conceitos clássicos isolados ao aplicarem-se situaçóes quânticas. Porém, o segundo caso coloca problemas de não-contradição intrínseca, para fazer frente aos quais é ilusório recorrer ao princípio de indeterminação, por duas razóes: por um lado, porque este é uma tomada de consciência de uma situação do primeiro tipo, que não apresenta nenhum nexo evidente com as do segundo; em segundo, porque a «compatibilidade lógica» entre os conceitos não pode estar assegurada pelo simples facto dos mesmos, não podem ser confrontados directamente no terreno experimental, por causa da indeterminaçáo das «medidas quânticas». ${ }^{24}$

3.4 Foi no Congresso de Como que Bohr formulou, pela primeira vez, a ideia de complementaridade, a mesma que aparecia como enunciado de uma

23 Cf. BOHR, N.; PAIS, A. Niels Bohr's Times: in Physics, Philosophy, and Polity, Clarendon Press, Oxford, 1991, 425-427.

${ }^{24}$ Cf. AGAZZI, E. Temas y problemas de Filosofia de la Física, tradução do francês, Editorial Herder, Barcelona,1978, pp. 311-312. 
necessidade para considerar tão só como complementares, a nível quântico, certos conceitos, que a nível clássico eram compatíveis e se acostumavam a empregar simultaneamente a propósito dos mesmos acontecimentos.

Assim, Bohr considerou a localização espacio-temporal, por um lado, e causalidade pelo outro, náo conseguindo determinar mais a sua formulação, porque não era possível na época, que só pode lograr-se precisamente depois do enunciado do princípio de Heisenberg: "A natureza intrínseca da teoria quanta, diz Bohr, obriga-nos a considerar a coordenação espacio-temporal e a afirmação de causalidade, cuja união caracteriza a teoria clássica, como aspectos complementares e mutuamente excluintes da descrição, os quais simbolizam a idealização da observação e da definição». ${ }^{25}$

Até aqui não se observam traços do uso da complementaridade para justificar o uso de conceitos classicamente incompatíveis. Quando Bohr concebeu a ideia de complementaridade, pretendeu estabelecer o balanço do estado da microfísica da época.

Até 1925, o formalismo da Mecânica Quântica consistia essencialmente num esquema simbólico, que permita, de acordo com o princípio da correspondência, (considera uma certa média das grandezas clássicas, tomadas sobre o conjunto dos estados não estacionários, que são intermédios entre o estado estacionário final, que correspondem à risca espectral considerada) ${ }^{26}$ prever certos resultados que se poderiam obter a partir de condiçóes especificadas em termos de conceitos clássicos. Assim, o princípio de complementaridade declara, de modo explícito, mas genericamente, a necessária situaçáo de imprecisão, que acompanha o uso destes conceitos. Muito pouco tempo depois, o princípio de indeterminação proporcionaria uma formulação quantitativa precisa da mesma afirmação, constituindo, desta maneira, uma confirmação do princípio da complementaridade, entendido de acordo com esta primeira interpretaçáo. Quando mais tarde, pela consequência de bem conhecidas vicissitudes, de tipo teórico e experimental, tiveram que enfrentar-se as alternativas de tipo "onda-corpúsculo», parecem ver nelas uma situação análoga à precedente. Isto é, foram interpretadas a partir do exemplo familiar, dado

25 Cf. HEISENBERG, W. Philosophic Problems of Nuclear Science, Faber and Faber, London, 1978, pp. 27-106.

26 Cf. DE BROGLIE, L. La Fisica Nueva y los Cuantos, traducción del francés, Editorial Losada, Buenos Aires, 1944, 157. 
por dois conceitos clássicos, que se deveriam supor como complementares. É absolutamente necessário compreender, escreve N. Bohr, que no exame de toda a experiência física,devem expressar-se ora pelas condiçôes experimentais, ora pelos resultados das observaçóes, os mesmos meios de comunicação, que se usam na física clássica. ${ }^{27}$

Também outros autores, que adoptam posturas deste tipo, como Heisenberg, Born, Jordan, assinalaram rapidamente a dependência da teoria dos quanta relativamente à linguagem clássica. Esta circunstância seria justificada pelo facto dos aparelhos experimentais, que nós devem valer para investigar os fenómenos subatómicos, e os seus comportamentos devem ser descritos classicamente.

É natural que os conceitos clássicos tão só podem encontrar uma aplicação aproximada, mesmo que, por outra parte, claro que não se pode fazer outra coisasenão que tomar nota desta situaçáo e contentar-se com o facto de que precisamente a imprecisão desta aplicaçáo constitui uma garantia contra um choque directo entre conceitos contraditórios.O carácter de indeterminação, inerente ao princípio de Heisenberg, fazem servir para conceitos, que não têm realmente nada a ver com o dito princípio, tais como os de onda e os corpúsculos, graças a um equívoco subtil, mas que não é difícil colocar em evidência. Finalmente, entre a ascensão e a queda da complementaridade de N. Bohr, teremos que dizer que tal princípio necessitaria de ser generalizado em virtude da teoria da unificação da Física. Contudo, será conveniente referir que este princípio não é de índole científica, dado que não tem confirmação experimental, no mundo da física, mas apresenta-se unicamente como enunciado metafísico. A complementaridade ontologicamente diz que a natureza sicut dynamicam essentiam esse revela-se em duas «imagens» ou duas expressóes recíprocas diadicamente, como: onda-partícula. Seria como se a natureza tivesse uma dupla essência, com o mesmo esse ontologicus. . A física teórica e a filosofia da natureza são "complementares» para a resolução dos problemas quânticos. A física desvenda, pela Análise Matemática, as estruturas e as próprias essências dos entes físicos e a Filosofia da Natureza estuda os problemas do ser (existir) e o devir temporal dos entes físicos (partícula-onda). O problema ontológico da complementaridade coloca esta dualidade complementar: essência dinâmica e existir.

27 Cf. HERMANN, G. Les fondements philosophique de la mécanique quantique, traduit par A. Schmell, Librairie Philosophique J. Vrin, Paris, 1996, 77-79. 
Em qualquer hipótese, implica, na sua essência existencial, ou na mudança a relação biunívoca:

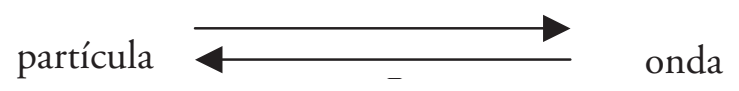

A relação metafísica será dada por dois princípios de ser: o material e o formal. Com efeito, revelam-se novos graus de ser e propriedades especificamente diferentes.

Segundo a «métrica de Schroedinger», as leis do movimento da partículaonda traduzem a potência como limite do ser métrico dual, onde uma potência se transforma noutra potência. A perfeição do ser mutável é o acto, que revela a "complementaridade ontológica», ou síntese, como defendeu Hegel, ao dizer que esta supóe uma "trilogia dialéctica»:

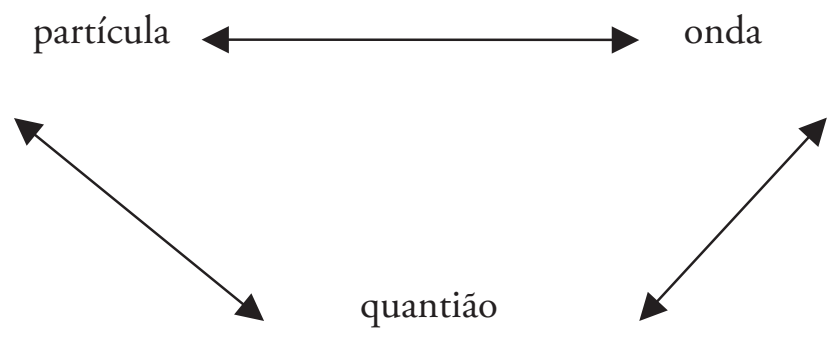

O quantião é o movimento e a posição da partícula-onda, que são determinados em função do princípio de incerteza quer para a quantidade matéria, quer para a energia, respectivamente. O quantiáo marca, sinteticamente, o sentido ontológico da complementaridade como limite da perfeição quântica. Poderemos dizer que se trata de uma "potência de potência». Naturalmente que o quantiáo vive numa causalidade probabilística de n-efeitos: partícula $\rightarrow$ onda $\rightarrow$ partícula. Este determina a causalidade circular ou «recíproca», a qual postula n-efeitos. Segundo o princípio da complementaridade surgem diferentes imagens para a natureza, que gnoseologicamente são as certezas probabilísticas, que têm como fundamento a evidência aleatória quântica. Naturalmente, hoje a Mecânica Quântica é, também, matemática e filosofia aplicadas. Com a complementaridade a natureza é uma, com duas faces ou «imagens»: a corpuscular e a ondulatória. As duas imagens não são uma sem a outra e, por isso, convivem, na natureza, dualmente, como determina a ontologia regional da Mecânica Quântica. 


\section{Interpretação de Copenhagen e a complementaridade}

4.1 A interpretação de Copenhagen é quase universalmente aceite e diz que a realidade objectiva se esfumou, dado que a Mecânica Quântica não representa partículas, antes o nosso conhecimento, a nossa observação, a nossa consciência das partículas.

O físico F. Bopp escreveu, sobre a leitura de Copenhagen, que as consideraçôes não supôem nenhuma alteração do conceito matemático de complementaridade, porque este físico interpreta o formalismo teórico-quântico como extensão da mecânica estatística clássica, como se fosse uma teoria dos conjuntos. Há muito tempo que a interpretação de Copenhagen foi abandonada e a maioria dos físicos não lhe presta qualquer atenção. ${ }^{28} \mathrm{~A}$ mecânica quântica era considerada pelos seus partidários como a forma final desta teoria electromagnética da matéria. O formalismo de Copenhagen considera a teoria dos electrôes e dos protôes e, portanto, como a teoria da constituição dos átomos, do sistema periódico dos elementos, e de suas propriedades físicas e da ligação química. Esta teoria, de que a matéria consiste em protôes e electrōes, morreu desde há alguns anos a esta parte. A sua enfermidade começou com a descoberta do neutráo e do positáo (que as autoridades de Copenhagen se negaram a aceitar o princípio), recebeu o golpe de misericórdia pela descoberta dos níveis de interacção, de que as forças electromagnéticas constituem uma entre quatro:

1. forças nucleares;

2. forças electromagnéticas;

3. interacçóes débeis de desintegração;

4. forças de gravitação.

Também se perdeu a esperança de resolver, dentro da Mecânica Quântica, problemas clássicos da teoria electromagnética, tais como: a explicação da carga electrónica. Perante uma tal situação poderemos considerar a luta titânica entre Einstein e Bohr. O problema colocado por Einstein foi se a Mecânica Quântica era — completa—. Einstein dizia que não e Bohr dizia que sim. ${ }^{29}$ Einstein tinha razão, mas quem ganhou a batalha fora Bohr. Esta opinião persistiu, em grande

${ }^{28}$ Cf. SCHILPP, P. A. Albert Einstein: philosopher-scientist, Princeton University, New York, 1949, 665-668.

${ }^{29}$ Cf. EINSTEIN, A et alii «Can Quantum Mechanical Description of Physical Reality be considered complete», in: Physical Review, 47 (New York, 1935), 777-780. 
medida, porque o ataque de Einstein à asserção de Bohr sobre a — completude- da Mecânica Quântica fora interpretada pela Escola de Copenhagen, como um ataque à Mecânica Quântica e à sua consistência. Daqui ser estranho aceitar a identificação da interpretação de Copenhagen como a teoria quântica e à mudança que fez Bohr do problema da completude ou das correcçóes (ausência de contradição). Entretanto, Einstein ofereceu a sua própria interpretação (estatística) da teoria quântica, tendo aceite claramente o facto da sua consistência. ${ }^{30}$ Gnoseologicamente pensando, não é físico aceitar a ideia de que existem partículas que possuam posiçóes $(\Delta x i)$ e movimentos $(\Delta p i)$ definidos em qualquer momento do tempo dado e conceder que esses dados nunca poderão ser confirmados experimentalmente, por um capricho da natureza. Há que admitir que os físicos aplicam o formalismo da Mecânica Quântica a velhos problemas e aos métodos do formalismo, com muitas modificaçóes se se usam, em parte, na relação com problemas da teoria nuclear e da teoria das partículas elementares. A maioria dos experimentadores, mais preocupados com os limites da precisão dos seus resultados, não parecem estar preocupados relativamente à função do observador ou com respeito à sua interferência resultados do que se referiu, quando se trata de uma inovadora experiência clássica. Muitos físicos preferem uma nova teoria realmente. Aquilo que é necessário discutir, segundo a leitura de Copenhagen, no aspecto gnoseológico, encerra-se exactamente na afirmaçáo de que, na teoria atómica, teremos que considerar o «observador» ou o "sujeito», como especialmente importante, porque a teoria atómica adquire, em grande medida, o seu carácter peculiar da interferência do sujeito ou do observador e dos seus meios para medir o objecto físico, que se investiga. Realmente, segundo N. Bohr, a interacçáo finita entre o objecto e os meios de medir desvia-nos de uma renúncia definitiva ao ideal clássico e uma reconsideração da nossa atitude, frente ao problema da realidade física. ${ }^{31}$ Heisenberg partilha que o requisito tradicional da ciência permite uma divisão do mundo entre sujeito e objecto (observador e observado). Esta suposição não é permissível em Física Atómica. A interacção entre o observador e o objecto causa mudanças incontroláveis no sistema, que está em observação, devido às mudanças descontínuas e características dos processos atómicos. Heisenberg sugere que será proveitoso reexaminar a discussão fundamental, tão importante

${ }^{30}$ Cf. BOHR, N. "The Quantum Postulate and the recent development of Atomic Theory», in: Nature, 121 (London, 1928), 580-590.

31 Cf. VON NEWMANN, J. Mathematical Foundations of Quantum Mechanics, At the University Press, Cambridge,1949, 1955, 45-56. 
para a epistemologia, quanto a dificuldade em separar os aspectos subjectivos e objectivos do mundo. ${ }^{32}$

Ainda que os conceitos possuam uma grande capacidade de sugestão e influência no desenvolvimento posterior da teoria, não é o sistema conceptual senão a teoria a que tem importância real para o aspecto científico. Já a teoria não é simplesmente um instrumento, encontra-se interessada na sua verdade ou aproximação desta. O sistema conceptual é intercambiável e é um entre os variados instrumentos possíveis, que podem usar-se para formular a teoria. $\mathrm{O}$ sistema conceptual proporciona uma linguagem para a teoria, quiçá uma linguagem melhor e mais simples. ${ }^{33}$

H. Hertz disse, e foi repetido por Wittgenstein, que em ciência criamos «imagens» para nós, dos factos ou da realidade, e escolhemos as nossas «imagens», de tal maneira que as consequências são necessariamente lógicas, onde as imagens estão de acordo com as consequências necessariamente naturais (die naturnotwendigen Folgen) dos objectos e das imagens reais.Mach sugeriu que deveríamos interpretar as imagens de Hertz como conceitos. A concepção de Bohr parece similar, quando fala da «imagem corpuscular» e da «imagem ondulatória», que revelam a influência de Hertz e de Mach.Mas, as imagens não têm importância. Possuem pouca importância se são mais ou menos sinónimos dos conceitos e de pouco significado, que representam as teorias.

Uma teoria não é uma imagem. Não necessita ser entendida por meio de «imagens visuais». Assim, entendemos uma teoria, se compreendemos o problema para cuja solução se concebeu e se entendemos a forma, pela qual se resolve melhor ou pior do que os seus competidores formais.Estas consideraçóes são importantes por causa da disputa constante entre «imagem corpuscular»e a «imagem ondulatória» e a sua suposta dualidade ou "complementaridade» e sobre a suposta necessidade, afirmada por Bohr, de usar «imagens clássicas», por causa da impossibilidade de entender e de visualizar os objectos atómicos. Toda esta discussão sobre as «imagens» não têm a mais pequena relação com a física, nem com as teorias físicas, nem com o entendimento das mesmas. De grande significado será a nossa carência de conhecimento, descoberta por Heisenberg

32 Cf. HEISENBERG, W. K. The Physical Principles of the Quantum Theory, Blackwell, London, 1930,45-88.

33 Cf. POPPER, K. P. A Teoría Cuántica y el Cisma en Física, traducción de M. S. Vidal, Editorial Tecnos, Madrid, 1982, 67-74. 
e formulada no princípio de indeterminação ou de «incerteza», que nos obriga a adoptar uma teoria probabilística.O grande problema quântico consiste em tomar a "função de distribuiçãa", isto é, uma função de medida estatística, que caracteriza algum espaço mestral e tratá-la como se fosse uma propriedade física dos elementos da população. Não há relação simétrica e, portanto, não existe dualidade entre partícula e onda ou entre as partículas e o seu campo correspondente. Infelizmente, muitos físicos falam como se a função de distribuição fosse uma propriedade dos elementos da população, em questão. Não se distinguem entre categorias ou tipos de coisas totalmente diferentes e baseia-se na suposição.

A chamada onda-função $\psi$ pode ser identificada como a fórmula matemática de uma função:

$$
f(P, d P / d t)
$$

que é expressão de uma função de distribuição probabilística P, onde:

$$
f=\psi=\psi(q, t) ; \quad P=|\psi|^{2} .
$$

É uma função de distribuição de densidade. O elemento, em questão, tem as propriedades de uma partícula. A forma de onda — no espaço de configuração- da função $\psi$ é, deste ponto de vista, uma espécie de acidente, que coloca um problema à teoria das probabilidades, mas que náo tem quase nada a ver com as propriedades físicas das partículas. Estas fórmulas são elementos estatísticos validamente deriváveis da teoria quântica. As fórmulas de Heisenberg estabelecem certos limites inferiores para a «dispersão estatística» dos resultados de sucessões de experiências, apresentando-se como «relações estatísticas de dispersão». Para contrastar estas relaçôes de dispersão teremos que ser capazes de efectuar mediçóes, que sejam muito mais precisas do que a amplitude da dispersão. Por certo medimos o momento $\mathrm{p}_{\mathrm{x}}$ de uma partícula considerada por meio da sua posição na película do espectógrafo. Por causa da repetida afirmação de Bohr, as mediçóes do momento e das mediçôes da posição são incompatíveis ou complementares, devido à exclusão mútua dos procedimentos experimentais, que permitem a definição inequívoca das qualidades físicas complementares. Os procedimentos experimentais, como refere Bohr, excluem-se mutuamente, porque as mediçóes do movimento requerem uma écran móvil, enquanto que as medições de posição requerem um écran fíxo ou uma placa fotográfica fixa. Era precisamente este facto que se negava constantemente, dado que Heisenberg fez 
dele uma questão de crença pessoal. Bohr e a Escola de Copenhagen insistiram em que um electrão não pode ter uma posição e um momento nítidos ao mesmo tempo. Este dogma está no núcleo da tese de Bohr, de que a teoria quântica é completa, presumivelmente no sentido de que esta permite que uma partícula não pode ter propriedades, que a teoria não permite medir. ${ }^{34}$ Naturalmente, a interpretação do formalismo da Mecânica Quântica está in stricto sensu relacionada com a interpretação do cálculo de probabilidades, sendo este entendido como cálculo formal, que contém leis formais, como

$$
0 \leq p(\mathrm{a}, \mathrm{b}) \leq 1
$$

Aquilo que a probabilidade significa e o que representam os argumentos a e b, ficará aberto à interpretação. Existem, com efeito, uma variedade de interpretaçóes, quer subjectivas, quer objectivas. A Mecânica Quântica é per naturam suam uma teoria estatística aplicada, dado que tem de trabalhar com variáveis aleatórias holísticas, criando uma nova visão para a natureza. Além dos aspectos gnoseológicos e epistemológicos, teremos de proceder à fundamentação lógica.

4.2 A teoria estatística pode ser referida como caracterizada pelo conjunto de grandezas físicas, formando uma estrutura algébrica de um espécie, conjuntamente com um algoritmo para definir as probabilidades para obter valores possíveis destas grandezas. A teoria quântica (pela complementaridade de Bohr e incertezas de Heisenberg) implica um conjunto de «estados estatísticos», que assinalam as probabilidades para uma sentença teórica: $\operatorname{val}(A) \in S$.

As duas grandezas físicas, $\mathrm{A}$ e $\mathrm{B}$, são equivalentes numa teoria estatística, como no caso:

$$
p_{w}(\operatorname{val}(A) \in S)=p_{w}(\operatorname{val}(B) \in S) .
$$

Para todos os estudos estatísticos, $\mathrm{W}_{\mathrm{e}}$, para o conjunto de Borel $\mathrm{S}$, onde $\mathrm{g}: \mathrm{R} \rightarrow \mathrm{R}$ é uma função de Borel valorizada como real, quando x e $\mathrm{g}(\mathrm{A})$, são estatisticamente equivalentes. Relativamente, a esta relação de equivalência, as duas

${ }^{34}$ Cf. HEISENBERG, W. K. The Physical Principles of the Quantum Theory, Blackwell, London, 1930, 20. 
grandezas $\mathrm{A}_{1}$ e $\mathrm{A}_{2}$ são consideradas compatíveis, se e só se existir uma terceira grandeza, $\mathrm{B}$, e como função de Borel $\mathrm{g}_{1}: \mathrm{R} \rightarrow \mathrm{R}$ e $\mathrm{g}_{2}: \mathrm{R} \rightarrow \mathrm{R}$, tal como:

$$
\begin{aligned}
& A_{1}=g_{1}(B) ; \\
& A_{2}=g_{2}(B) .
\end{aligned}
$$

Esta definição de «compatibilidade» de duas grandezas é devida a Kochen e Specker.

Uma combinação linear de duas grandezas compatíveis pode ser definida via funçôes lineares associadas, como:

$$
a_{1} A_{1}+a_{2} A_{2}=\left(a_{1} g_{1}+a_{2} g_{2}\right) \cdot(B)
$$

onde $\mathrm{a}_{1}$, $\mathrm{a}_{2}$ sáo números reais, e simultaneamente o produto pode ser definido como:

$$
A_{1} A_{2}=\left(g_{1} g_{2}\right) \cdot(B)
$$

Com combinaçôes lineares e produtos de grandezas compatíveis definidas neste caminho, as grandezas de uma teoria estatística formam uma álgebra parcial.

Evidentemente se todas as grandezas de uma teoria estatística são compatíveis, a álgebra parcial é uma álgebra comutativa e o conjunto de grandezas idênticas será uma Álgebra de Boole. ${ }^{35}$ Usualmente, a medida de probabilidade entendeu-se como função conjunto normada, num campo - $\sigma$ de subconjuntos de um espaço $\mathrm{X}$, ou seja, um mapa: $\mathfrak{I} \rightarrow R$, satisfazendo as seguintes condiçôes:

$$
\begin{gathered}
p(0)=0 ; \quad p(R)=1 \\
0 \leq p(E) \leq 1 \text { para } E \in J \\
p\left(\bigcup_{i=1}^{\infty} E_{i}\right)=\sum_{i=1}^{\infty} p\left(E_{i}\right)
\end{gathered}
$$

35 Cf. KLEENE, S. C. Mathematical Logic, John Wiley \& Sons, New York, 1973, 10-26. 
onde $E_{i}$ é uma classe de conjuntos disjuntos em $\mathfrak{I}$, i. e., $E_{i} \cap E_{j}=0, i=j$. A tríplice relação $\langle X, J, p\rangle$ é referida como «espaço probabilístico». O conjunto $\mathrm{X}$ pode ser entendido como o conjunto de «outcomes» possíveis e distintos de uma experiência e o conjunto $\mathfrak{I}$ como o conjunto de acontecimentos, para que as probabilidades sejam garantidas. Equivalentemente, por causa do isomorfismo entre campos de conjuntos e as álgebras de Boole, o conceito de probabilidade desenvolve-se formalmente na Álgebra de Boole. No mesmo sentido, as probabilidades podem ser assinaladas em sentenças lógicas de Boole, determinando que as sentenças equivalentes logicamente são assinaladas pela mesma probabilidade. No caso da álgebra de Boole, há obviamente uma generalização. A medida de probabilidade é, no sentido generalizado, qualquer determinação dos valores entre 0 e 1 para os elementos de uma álgebra de Boole parcial, que satisfaz as condiçóes usuais para a medida de probabilidade em cada subconjunto compatível da álgebra booleana parcial. O algoritmo da Mecânica Quântica envolve a representaçáo dos estados estatísticos da teoria por meio de determinada classe de operadores no espaço de Hilbert, os operadores estatísticos e as grandezas físicas por meio de operadores hermenêuticos. As álgebras de Boole, para subespaços de um espaço de Hilbert, podem ser ordenado parcialmente pela inclusão de conjuntos. Uma álgebra de Boole de subespaços é «máxima» com respeito à sua ordem.

Um conjunto de sentenças corresponde à máxima álgebra de Boole de subespaços de $H$, sendo uma lógica de Boole. A lógica das sentenças, que são probabilidades assinaladas pelo algoritmo quântico, não é de Boole, existem subespaços incompatíveis ou equivalentemente, porque o conjunto de grandezas físicas não pode ser todo expresso como função de uma grandeza singular.

O juízo, que define um sentido lógico para a Mecânica Quântica, é nãobooleano, no sentido em que o valor da álgebra de Lindenbaum-Tarski é isomórfico para uma álgebra booleana parcial de subespaços de Hilbert. Logo, será acentuadamente mais do que uma reformulação de sentenças mais familiares, do que grandezas físicas da teoria, elaborada de uma álgebra não comunicativa, sendo opostas às grandezas físicas da Mecânica Clássica. As peculiaridades das relaçóes da estatística quântica e as anomalias que damos atenção são explicadas pelo apontamento dos caracteres não-booleanos da lógica das sentenças, em que as probabilidades são justificadas pela teoria quântica. Compreende-se a interpretação de Copenhagen da teoria como explicação proposta para estas anomalias. Assim, J. Bub explica o sentido e relação das incertezas de Heisen- 
berg com as álgebras de Boole e o sentido para a interpretação de Copenhagen pelas seguintes palavras: «Thus, Heisenberg's proposal is to understand the nonBoolean working logic of quantum mechanics in terms of the theoretical opacity of measurement disturbances. It is the claim that a certain theory of measurement is true that explains the appropriateness of a theory with a non- Boolean working logic for the description, and explanation of the behavior of microsystems. And this claim in turn is supported by arguments of the kind involved in Heisenberg's x-ray microscope thought experiment. The peculiarities of the quantum description of micro-events are taken to reflect, ultimately, the truth of a theory concerning the observability of micro-events». Os operadores estatísticos da Mecânica Quântica dividem-se em dois conjuntos: um dependente e outro independente. Um operador estatístico «idempotente» é um operador-projecção num subespaço 1-dimensional e existe uma correspondência biunívoca entre o conjunto de espaços 1-dimensional de $H$ e o conjunto de operadores estatísticos «idempotentes» em $H$. Mas, cada subespaço 1-dimensional pode ser associado com um «vector-unidade» em $H$, e, também, para operadores estatísticos idempotentes. $\mathrm{O}$ algoritmo para probabilidade determinadas pode ser formulado em termos de espaços de Hilbert vectorialmente:

$$
p_{\psi}(\operatorname{val}(A) \in S)=\left\|P_{A}(S) \psi\right\|^{2}=\left(\psi, P_{A}(S) \psi\right) .
$$

No caso em que A tem um espectro directo com «egenvalues» não-degenerados, este transforma-se em :

$$
p_{\psi}(\operatorname{val}(A) \in S)=\sum_{a i \in S}\left\|P_{a i} \psi\right\|^{2}=\sum_{a i \in S}\left|\left(\alpha_{i}, \psi\right)\right|^{2},
$$

onde $P_{a i}$ é o operador- projecção dentro do subespaço 1-dimensional, expandindo pelos eigenvalues $\alpha_{\mathrm{i}}$ correspondendo ao valor $\mathrm{de}_{\mathrm{i}}$.

Agora, os operadores estatísticos idempotentes são exprimíveis como a soma convexa de dois ou mais operadores estatísticos diferentes, i. e., se W é idempotente,segundo:

$$
\begin{gathered}
W=p_{1} W_{1}+p_{2} W_{2} \\
\left(p_{1}+p_{2}=1\right) ; p_{1}>0 ; p_{2}>0
\end{gathered}
$$

quando: $W=W_{1}+W_{2}$. 
Isto significa que a probabilidade determinada, por W, para as sentenças não pode reduzir-se a uma soma convexa de probabilidades, definida em $S$ por operadores estatísticos diferentes de W, i. e.:

$$
p_{w}(S) \neq p_{1} w_{1}(S)+p_{2} w_{2}(S)
$$

para qualquer $p_{1}, p_{2}, w_{1}$ e $w_{2}$. Os operadores estatísticos não - idempotentes sáo todos expressíveis como somas convexas de operadores estatísticos «idem» potentes. Os operadores estatísticos de um conjunto convexo ligam-se aos operadores estatísticos puros como «extrema». A dispersão $\Delta w A$, de uma grandeza física $\mathrm{A}$, é definida para cada operador estatístico $\mathrm{W}$ por:

$$
(\Delta w A)^{2}=\operatorname{Exp}_{w}\left(A-\operatorname{Exp}_{w}(A)\right)^{2}=\operatorname{Exp}_{w}(A)^{2}-\left(\operatorname{Exp}_{w}(A)\right)^{2},
$$

onde $\operatorname{Exp}_{w}(A)$ é o valor de expectação de A, i. e.:

$$
\operatorname{Exp}_{w}(A)=\int_{-\infty}^{\infty} r d\left(\operatorname{Tr}\left(W P_{A}(r)\right)\right)=\operatorname{Tr}(W A)
$$

No caso de um operador estatístico puro corresponde a um vector $\psi$, assim poderemos escrever:

$$
(\Delta \psi \cdot A)^{2}=\operatorname{Exp}_{\psi}(A)^{2}-\left(\operatorname{Exp}_{\psi}(A)\right)^{2}
$$

e:

$$
\operatorname{Exp}_{\psi}(A)=\int_{-\infty}^{\infty} r d\left(\psi, P_{A}(r) \psi\right)=\left(\psi, A_{\psi}\right)
$$

A relação de Heisenberg, como relação recíproca entre as dispersôes de duas grandezas incompatíveis $\mathrm{A}, \mathrm{B}$, satisfaz uma relação de comutação:

$$
A B-B A=i h I / 2 \pi, \text { que }
$$

poderá ser derivada como um teorema da Mecânica Quântica:

$$
\Delta_{\psi} A \cdot \Delta_{\psi} B \geq h / 4 \pi(\text { para cada } \psi)
$$


Então, os operadores estatísticos formam um conjunto convexo a fortiori:

$$
\Delta_{w} A \cdot \Delta_{w} B \geq h / 4 \pi
$$

para todos os operadores estatísticos impuros W. Isto será um corolário imediato para este teorema, que não é um operador estatístico W, como livre dispersão, para todas as grandezas $\mathrm{A}$, i. e., há um operador não-estatístico $\mathrm{W}$, que satisfaz a equação:

$$
\Delta_{w}(A)=0(\text { para todos os A })
$$

Estas deduções não se poderão aplicar ao princípio de complementaridade, dado que estes não se encontram na afirmação de N. Bohr.Segundo a lógica simbólica, o chamado princípio de complementaridade não se poderá referir como definição, nem como axioma, e, muito menos, como um teorema. ${ }^{36} \mathrm{~A}$ interpretação de Heisenberg providencia uma explanação para esta suficiência de estatísticas quânticas. Em particular, a ausência da dispersão de operadores estatísticos na teoria é entendida como reflectindo a impossibilidade física de assegurar valores verdadeiros,simultaneamente para proposiçóes incompatíveis em qualquer processo de medida, porque uma distribuição será incontrolável pelos valores de incompatíveis grandezas com A envolvida,em toda a medida de A. Classicamente, o valor da expectação de uma variável aleatória A no espaço de probabilidade $\langle X, J, p\rangle$ é definida por:

$$
\operatorname{Exp}(A)=\int_{x} A \cdot d p
$$

e a dispersão de A por:

$$
(\Delta A)^{2}=\int_{x}(a-\operatorname{Exp} A)^{2} d p=\operatorname{Exp}\left(A^{2}\right)-(\operatorname{Exp}(A))^{2}
$$

Uma medida da probabilidade de livre expressão p satisfaz a condição: $\Delta A=0$ para todos os $\mathrm{A}$. Em particular, $\Delta P=0$, surge para todas as variáveis aleatórias «idempotentes». Uma idempotente variável aleatória satisfaz a condição:

$$
P(x)^{2}=P(x) ; \text { para todos os } x \in X .
$$

${ }^{36}$ Cf. BUNGE, M. «Strife about Complementarity», in: British Journal for the Philosophy of Science, 6 (London, 1955), 11-12; 141-154. 
$P(x)=0$, ou 1. Entấo, $P . X \rightarrow\{0,1\}$ é uma função característica do conjunto de Borel: $E \equiv X$, então:

$$
\operatorname{Exp}(P)=\int_{x} P d p=p(E) .
$$

Agora,

$$
\Delta P=\operatorname{Exp}\left(P^{2}\right)-(\operatorname{Exp}(P))^{2}=\operatorname{Exp}(P)-(\operatorname{Exp}(P))^{2}=p(E)-p^{2}(E) .
$$

Assim, a medida da probabilidade da dispersão livre será a medida de 2-valores, uma determinação das probabilidades 1 ou 0 , para cada conjunto de Borel em $H$. Entretanto:

$$
p\left(E^{\prime}\right)=1-1(E),
$$

quando

$$
E^{\prime}=X-E
$$

e

$$
p(E \cap F)=p(E) p(F),
$$

para todos os conjuntos de Borel:

$$
E, F \subseteq X
$$

Pelo isomorfismo entre J e L, a álgebra de Lindenbaum-Tarski, como uma medida de probabilidade de dispersão livre em L, é a medida do 2-valor em $\mathrm{L}$. Mas, a medida do 2-valor em L é um homomorfismo 2-valor em L e corresponde a um ultra-filtro em L, para um conjunto de consistência máxima de proposiçóes. Uma probabilidade em dispersão livre, medida em espaço de face da Mecânica Clássica, corresponde ao ponto no espaço de face —um estado da mecânica quântica. Novamente encontramos o sentido do pensamento de J. Bub: «For Heisenberg, there are no dispersion-free statistical operators of the theory represent those, and only those, probability assignments that are compatible with our possible knowledge of the micro-level, in the light of the theoretical opacity of measurement there is no analogue in quantum mechanics of the classical mechanical state - the Boole an ultra filter, or dispersion-free probability measure — is taken to reflect the contingent truth of a theory concerning possible measurements at the micro-level. The pure statistical operators of the theory are compatible with 
maximal knowledge, not maximal truth. It is in this sense that vectors in Hilbert space are the legitimate successors in the quantum description to the classical states: they represent various possible totalities of situation in logical space that are maximal with respect to what can be known simultaneously. These are the state descriptions of quantum mechanics, and the impure statistical operators represent less than maximal knowledge, probability measures over quantum states». ${ }^{37}$

A versão de Heisenberg da interpretação de Copenhagen é caracterizada pela tese de que a mecânica quântica é quer estatística, quer completa, i. e., irredutivelmente estatística, no sentido que o "espaço de Hilbert» representa as descriçóes de estado, que são tão fechadas quanto possível nos«ultra filtros», entendidos com referência à teoria, que mede os distúrbios teoricamente opacos no micronível. Os vectores no espaço de Hilbert são interpretados como totalidades q-máxima de situaçóes, no espaço lógico, como totalidades das situaçóes cognoscíveis, que são máximas relativamente ao que pode ser conhecido simultaneamente. Relativamente, ao pensamento da complementaridade de N. Bohr, refere J. Bub: «Now, it would be quite wrong to understand Bohr's version of the Copenhagen interpretation as simply another story that explains why such - and - such totalities of situations are maximal in this sense, i. e., in terms of the wholeness of instrument and measured object, the ultimacy of classical concepts, as opposed to Heisenberg's story, which involves a theory about the irreducibility and uncontrollability of measurement disturbances. Bohr's position differs radically from Heisenberg's». ${ }^{38}$ Para N. Bohr, aquilo que é fundamental será a teoria da aplicabilidade dos conceitos. Um conceito é referido sob certas condições, a aplicabilidade das condiçóes, de dois conceitos diferentes, pode ser mutuamente exclusiva. A perspectiva de Bohr será o caso para o espaço-tempo e o momento de energia quanto aos conceitos da física clássica, isto é, as condiçôes para a aplicabilidade dos conceitos de espaço-tempo poderão excluir as condiçóes para a aplicabilidade dos conceitos do momento de energia. A Mecânica Quântica é uma generalização racional da mecânica clássica no seguinte sentido: cada sentença teórica $\operatorname{val}(A) \in S$ está associada como grupo dos conceitos do espaço-tempo ou com o grupo de conceitos do momento da energia, mas não com ambos. Uma sentença teórica expressa uma proposição se e só se as condiçóes de aplicabilidade dos conceitos associados são satisfeitos. Existem sempre relaçóes formais entre

37 Cf. FEYERABEND, J. «On a recent critique of Complementarity», in: Philosophy of Science, 35 (New York, 1968), 309-331.

38 Cf. BUB, J. "On the completeness of Quantum Mechanics», in: C. A. HOOKER (1987) Contemporary Research in the Foundations and Philosophy of Quantum Theory,.12. 
o princípio de complementaridade de Bohr e pela hermenêutica da Escola de Copenhagen, que está de acordo com o referido princípio.

\section{A Complementaridade pela leitura fenomenológica}

A partícula não é uma onda, e vice-versa, porque podemos localizá-la no decurso de uma observação e não é um corpúsculo porque, antes da observação, lhe é atribuído um conjunto de posiçóes e de velocidades; não pode ser nem uma coisa, nem outra, mas assemelha-se a ambas ao mesmo tempo. Na verdade, a questão de saber como representar a partícula per se nem sequer tem sentido para Bohr e Heisenberg. Verificaram que os conceitos clássicos de onda e corpúsculo são ao mesmo tempo incapazes e indispensáveis para descrever a realidade e concluem que toda a descrição unívoca de partícula se torna impossível no quadro do espaço e do tempo. Se medir é perturbar e conhecer é medir, como poderíamos definir uma partícula independentemente dos instrumentos de medida, através dos quais se manifesta a sua existência? A realidade de um electrão ou de um fotão restringe-se ao conjunto de possibilidades para obter certos resultados com o auxílio de medidas adequadas.

Teremos um conjunto de valores possíveis e de probabilidades de concretização pelas medidas de posição, um análogo para as medidas de velocidade, outro para as medidas de energia. Então verificamos que as probabilidades calculadas em Mecânica Quântica não correspondem às distribuiçóes de valores das diferentes grandezas físicas, que coexistem objectivamente. É aquilo que Bohr e Heisenberg exprimem ao dizer que estas distribuiçóes estatísticas só existem potencialmente e que é a própria medida, que torna efectiva esta ou aquela potencialidade. Para a Escola de Copenhagen, a partícula será apenas um conjunto das potencialidades de medida

Esta é a conclusão fundamental que resulta da interpretação das relaçóes de Heisenberg, como relaçóes de indeterminação. Os modelos clássicos de onda e de corpúsculo perdem todo o significado nesta nova teoria quântica. Bohr tentou conservar estas imagens, na sua interpretação, assim será este o significado do seu famoso princípio de complementaridade, frequentemente considerado como a chave conceptual da Mecânica Quântica. Com efeito, os conceitos clássicos de corpúsculo e de onda (monocromática) são incompatíveis e mesmo contraditórios. A natureza ondulatória da matéria e da luz implica um comprimento de onda e, portanto, uma velocidade bem definida, ao passo que a observação das 
propriedades corpusculares exige informaçôes precisas sobre a posição do electrão e do fotáo. Ora as relaçóes de Heisenberg afirmam precisamente que os nossos conhecimentos sobre a velocidade e a posição se prejudicam mutuamente, isto significa que a natureza corpuscular só poderá afirmar-se numa experiência à custa do aspecto ondulatório e reciprocamente.

Fenomenologicamente, graças às relaçôes de indeterminação, Bohr poderá dizer que os conceitos de onda e de corpúsculo, em princípio contraditórios, nunca se chocam na nossa descrição da natureza, e, portanto, o problema de uma escolha insolúvel nunca se porá. O electrão e o fotão comportam-se, às vezes, como uma onda, outras como um corpúsculo e, ainda às vezes como grãos, outras como campos, conforme o conjunto experimental com que os observamos. Sendo ambos indispensáveis à descrição da realidade, aparecendo sempre um com prejuízo do outro, ambos são mais ou menos potencialmente presentes. Bohr considerou complementares os conceitos de onda e de corpúsculo, assim como a velocidade e a posição de uma partícula, segundo o princípio de Heisenberg. Apesar das suas imprecisóes, o princípio da complementaridade fornece uma linguagem fenomenológica para a descrição dos microssistemas, segundo as ideias da Escola de Copenhagen.

Não devemos, pois, esquecer que, mesmo no âmbito destas ideias, ele não esgota a interpretação do formalismo quântico. Em particular não é capaz de dar resposta ao problema mais delicado e controverso da teoria, conhecido por redução do grupo de ondas pela medida.

Consideremos o caso simples de um electrão de massa m, deslocando-se livremente e acerca do qual possuímos certas informaçóes respeitantes ao visitante $\mathrm{t}_{0}$. Sabemos que se encontra entre os pontos de abcissas $x_{0}$ e $x_{0}+\Delta_{x 0}$, e está animado de uma velocidade compreendida entre $v_{0}$ e $v_{0}+\Delta_{v 0}$, entendendo-se que $\Delta_{x 0}$ e $\Delta_{v 0}$ satisfazem a relação de Heisenberg.

Mas, todos os nossos conhecimentos sobre o estado da partícula no $\mathrm{t}_{0}$ devem poder traduzir-se na expressão $\psi_{0}$ da função de onda, nesse instante e, segundo os princípios das interferências e da decomposição espectral, $\psi_{0}$ tem de ser aqui um grupo de ondas inserido, no intervalo de espaço $\left(x_{0}, x_{0}+\Delta_{x 0}\right)$, e conter, de acordo com a relaçáo de De Broglie, todos os comprimentos de onda compreendidos entre:

$$
\lambda_{0}=h / m v_{0} ; \quad \lambda_{0}^{\prime}=h / m \cdot\left(v_{0}+\Delta_{v 0}\right)
$$


A função $\psi_{0}$, que contém toda a nossa informação sobre o electrão, constitui a descrição do seu estado inicial.

Uma vez fixada a forma deste grupo de ondas, no instante $t_{0}$, a sua evolução será rigorosamente definida pela equação de Schroedinger. É precisamente esta evolução determinista da onda, que permite prever o estado do electrão em qualquer instante posterior e formular, portanto, determinam previsóes estatísticas sobre o resultado da medida de uma ou de outra grandeza. ${ }^{39}$ Poderemos calcular a intensidade da onda, num dado instante t e de acordo com o princípio das interferências, ficaremos a saber a probabilidade de detectar o electrão, em qualquer ponto do espaço, onde a intensidade da onda náo seja nula. Mas, admitamos agora que queremos por à prova essa previsão, medindo de facto a posição do electrão no instante t. Poderemos verificar a sua presença pelo aparecimento de uma pequena mancha num dado ponto $\mathrm{x}$ de uma chapa fotográfica, montada para o efeito e verificar tratar-se de um ponto, onde se previra que a intensidade da onda, não seria nula. Repitamos a experiência muitas vezes, com electróes sempre colocados nas mesmas condiçóes iniciais, de modo que o seu estado seja sempre representado pelo mesmo grupo de ondas: veremos aparecer na chapa uma série de manchas nos pontos $x_{1}, x_{2}$ e $x_{3}$ e poderemos confirmar a exactidão do princípio das interferências, verificando que a densidade das manchas em cada região da chapa será na verdade proporcional à intensidade calculada para a onda. Recordemos que estas experiências, de que voltaremos a falar, confirmam a teoria.

Com efeito, segundo a Escola de Copenhagen, o electrão não possui posição determinada antes da medida, visto que estão potencialmente espalhados por toda a extensão da onda $\psi$. Precisamos, então, de saber por que razão ele se manifesta como entidade bem localizada. A medida da posiçáo de um electráo, com o auxílio de uma chapa fotográfica, leva-nos a representá-la por um grupo de ondas muito bem localizadas, correspondendo praticamente às dimensóes da pequena mancha negra que observamos; mas, antes da medida, o electrão era representado por um outro grupo de ondas, cujas dimensóes podiam ser muito grandes. É, pois, necessário compreender como pode este grupo de ondas tornar-se instantaneamente quase natural. É evidente que a interpretação imediata dada, do ponto de vista de Bohr, para esta redução do grupo de ondas (grupo de probabilidades), consiste em tornar responsável por ele o aparelho de medida. Constatamos assim que, em virtude da existência da constante h, não é possível

39 Cf. ANDRADE, J. A.; LOCHAK, G. Quanta, grãos e campos, tradução do inglês, Sá da Costa, Lisboa, 1969, 126-127. 
observar uma partícula sem perturbar o seu estado. Dir-se-á então que a própria chapa fotográfica concretiza uma das localizaçóes potenciais do electrão ou, mais genericamente, é a interacção da partícula com o aparelho de medida, que produz a redução brutal do grupo de probabilidades. Esta explicação é perfilhada, mais ou menos explicitamente, por um grande número de autores, que se reclamam da Escola de Copenhagen..$^{40}$ Deste modo, Bohr opóe à descrição unívoca da natureza, desenvolvida pela física clássica, uma descriçáo por pares de conceitos ou variáveis complementares, que ele considera consequência inevitável da lei dos quanta. Os dois exemplos que acabamos de citar (onda-corpúsculo e posição-velocidade) são os mais importantes, mas podem encontrar-se outros, muito embora se chegue, por vezes, a enunciados nebulosos como o do carácter complementar da causalidade e da descrição espacio-temporal. Tentou-se estender estas ideias a outras disciplinas, principalmente à biologia, à psicologia e à sociologia, mas o mínimo que podemos dizer é que o resultado destas extrapolaçôes não é muito convincente, ${ }^{41}$.

\section{Conclusão}

Devemos reconhecer que a descoberta de Bohr, ao apresentar o princípio da complementaridade, leva-nos a compreender os aspectos contraditórios dos conceitos de onda e de partícula, ao descreverem a mesma realidade,que poderá ser apaziguada. Segundo Niels Bohr, esta reconciliação permite modificaçôes dos atributos clássicos, com os quais nós dotamos as ondas e as partículas, porque uma das imagens apresenta-se como imprópria para a descrição dos acontecimentos. Conduzido pelo facto empírico da natureza dual da matéria, Bohr reduziu estes aspectos da dualidade de imagens da natureza a um princípio da complementaridade.

Desta sorte, a natureza, como partícula e como onda, será considerada nos aspectos complementares da matéria. Ambas as imagens são necessárias para uma descrição da natureza, o que levou a que Bohr generalizasse o princípio da complementaridade a outras áreas da conduta humana, considerando-se de grandes potencialidades não só no mundo físico, como também, na história humana e na epistemologia. Mas, a batalha mais violenta que Bohr teve de travar foi no âmbito das implicaçóes filosóficas do princípio da Mecânica Quântica e seus fundamentos conceptuais. A doutrina de Bohr ia na linha de que a mecânica

40 Cf. MERZBACHER, E. Quantum Mechanics, John Wiley and Sons, New York, 1963, 7-8.

${ }^{41}$ Cf. POPPER, K. La théorie quantique et le schisme en Physique, traduction de linglais pour E. M. DISSAKI, Éditeurs des Sciences et des Arts, Hermann, 1996, 173. 
quântica pressupóe a física clássica para a sua verdadeira formulação. ${ }^{42}$ Mas, esta tentativa falhou com os mais recentes progressos da Mecânica Quântica, permitindo, assim, que a "complementaridade» se coloque somente como princípio filosófico e não como axioma da Mecânica Quântica. Niels Bohr confundiu os problemas ontológicos, com questóes onde os conceitos estão relacionados com a «realidade». Segundo a sua opinião a "comunicabilidade» é fundamental nas questóes do conhecimento, tal como asseverava: «Our task is not to penetrate into the essence of things, the meaning of which we don't know anyway, but rather to develop concepts which allow us to talk in a productive way about phenomena in nature». ${ }^{43}$ Assim, se conclui tratar-se de um princípio gnoseológico, que determinou algumas generalizaçóes e extrapolaçóes, que não resolvem muitas questóes, como as que se prendem com a temática da «consciência», sendo uma tentativa mais epistemológica do que ontológica. O princípio da complementaridade de N. Bohr marcou a evolução e os fundamentos filosóficos da Mecânica Quântica, enquadrando-se no espírito da Interpretação de Copenhagen.

Tratou-se da procura de apresentar uma forma de «dualismo físico» (relação recíproca entre partícula-onda), que se poderá fundamentar no «dualismo ontológico».

Segundo A. Pais, no ensejo de resumo e de síntese das aplicaçóes e extrapolaçóes da complementaridade, poderemos asseverar: «His general contributions to the general issues of human culture are not new and original, yet beautifully convey Bohr's position that complementary carries lessons of tolerance and of openness toward all the world. His thoughts on biology have not born fruit. Finally, I hope that the spirit of this sketch on Bohr's philosophy reflects on of his examples of complementarity between reason and sentiment». Múltiplas serão sempre as extrapolaçóes da complementaridade, até porque se inscrevem gnoseologicamente nos conceitos duais, que determinam o conhecimento da «realidade física».

\section{Bibliografia}

Sousa Alves, V. M. (1994). "Crítica da Mecânica Quântica», in: Revista Portuguesa de Filosofia, 50 (Braga, 1994), 28-39.

Boнr, N. (1965). «The structure of the atom», in: Nobel Lectures on Physics,Amsterdam: Elsevier Publishing Company.

${ }^{42}$ Cf. Ibidem, 8-9.

43 Cf. PAIS, A. Niels Bohr's Times: in Physics, Philosophy, and Polity, 446. 
Inenberry, E. (1962). Quantum Mechanics, for mathematicians and Physicists, Oxford University Press.

Heisenberg, W. (1958). Physikalische Prinzien Der Quantentheorie, Mannheim : Bibliographisches Institut.

Born, M.(1986). Física Atómica, Tradução Do Inglês Por Egídio Namorado, 4a Edição, Lisboa: Fundação Calouste Gulbenkian.

Heisenberg, W. et alii (1960). Discussione sulla fisica moderna, traduzione dal tedesco, Torino: P. Boringhieri.

Bohr, N. (1922). The Theory of Spectre and Atomic Constitution, Cambridge: At the University Press.

Bunge, M.(1973). Philosophy of Physics, Dordrecht: D. Reidel Publishing Company.

Schiff, L. I. (1955). Quantum Mechanics, New York: Mac Graw-Hill.

Sakurai, J. J. (1998). Modern Quantum Mechanics,New York, Addison-Wesley Publishing Company,

Dirac, P. A. M. (1958). The Principles of Quantum Mechanics, Oxford,Clarendon Press

Pauli, W. (1973) Pauli Lectures on Physics, volume 5, Wave Mechanics, translated by H. R. Lewis and S. Margulies, Cambridge, MIT Press

Von Weizshecker, C. F. E. (1991). «El significado de la teoría cuántica», in: Analogia, 5, 2 (México, 1991) 10-18.

Bohr, N. (1981). Collected Works, volume 2, edited by U. Hoyer, Amsterdam,,NorthHolland Publishing Company.

Heisenberg, W. (1958) Physics and Philosophy, London,George Allen and Unwin.

Bohr, N.; Pais, A. (1991). Niels Bohr's Times: in Physics, Philosophy, and Polity, Oxford, Clarendon Press.

Agazzi, E. (1978). Temas y problemas de Filosofía de la Física, tradução do francês, Barcelona, Editorial Herder.

Heisenberg, W. (1978). Philosophic Problems of Nuclear Science, London, Faber and Faber.

De Broglie, L. (1978). La Fisica Nueva y los Cuantos, traducción del francés, Buenos Aires,Editorial Losada.

Hermann, G. (1996). Les fondements philosophique de la mécanique quantique, traduit par A. Schmell, Paris, Librairie Philosophique J. Vrin.

Schilpp, P. A. (1949). Albert Einstein: philosopher-scientist, New York, Princeton University. 
Einstein, A et alii (1935). "Can Quantum Mechanical Description of Physical Reality be considered complete», in: Physical Review, 47 (New York, 1935), 777-780.

Bohr, N. (1928). "The Quantum Postulate and the recent development of Atomic Theory», in: Nature, 121 (London, 1928), 580-590.

Von Newmann, J. (1955). Mathematical Foundations of Quantum Mechanics, Cambridge, At the University Press.

Heisenberg, W. K. (1930) The Physical Principles of the Quantum Theory, London, Blackwell.

Popper, K. P. (1982). A Teoría Cuántica y el Cisma en Física, traducción de M. S. Vidal, Madrid, Editorial Tecnos.

Heisenberg, W. K. (1930). The Physical Principles of the Quantum Theory, London, Blackwell.

Kleene, S. C. (1973). Mathematical Logic, New York, John Wiley \& Sons.

Bub, J. (1983). "On the completeness of Quantum Mechanics», in: C. A.Hooker (1983) Contemporary Research in the Foundations and Philosophy of Quantum Theory, Dordrecht,D. Reidel Publishing Company.

Feyerabend, J. (1968). "On a recent critique of Complementarity», in: Philosophy of Science, 35 (New York, 1968), 309-331.

Andrade, J. A.; LochaK, G. (1969). Quanta, grãos e campos, tradução do inglês,Lisboa, Sá da Costa.

Merzbacher, E. (1963). Quantum Mechanics, New York: John Wiley and Sons.

Popper, K.(1996). La théorie quantique et le schisme en Physique, traduction de linglais pour E. M., Dissaki, Paris : Hermann.

Recibido : 11/02/2012

Aceptado : 27/11/2012 